\title{
Investigation on the performance of innovative powdered activated carbon hybrid microbial fuel cell in treating palm oil mill effluent
}

\author{
J Y Lee, P F Lim, P K Lo, M J K Bashir, H Nisar, W P Teoh and C A Ng* \\ Faculty of Engineering and Green Technology, University of Tunku Abdul Rahman, 31900 Kampar, Perak, Malaysia.
}

\begin{abstract}
Performance of nine 0.5L microbial fuel cells (MFCs) with and without powdered activated carbon (PAC) and cultivated at different sludge retention times (SRTs) with different feed concentrations were studied and compared for their effects on wastewater treatment, biogas and power productions. The best MFC could remove the chemically oxy gen demand (COD) from the palm oil mill effluent (POME) up to 64.4\%. This study also showed that biogas could be better produced by the MFCs which were fed with relatively higher feed concentration compared to the MFCs fed with relatively lower feed concentration. However, it was found that the power production for the MFCs fed with relatively lower feed concentration had better power density production compared to the MFCs fed with the relatively higher feed concentration. In addition, all the MFCs cultivated at longer SRTs with PAC could perform better in terms of biogas production, COD removal rate and power production.
\end{abstract}

Keywords: Microbial fuel cell; sludge retention time; palm oil mill effluent; powdered activated carbon

\section{Introduction}

Microbial fuel cell (MFC) technology can harness the power energy by converting the chemical energy in the organic compounds to electrical energy through microbial reactions under anaerobic conditions [12]. Anaerobic digestion in MFC is also able to generate biogas whilst treating the wastewater. The energy harvested and biogas produced from MFC can be used to offset the power input needed for treatment plant [1]. However, the performance of MFC is limited by various factors such as sludge retention time (SRT), hydraulic retention time (HRT), $\mathrm{pH}$, temperature and feed concentration. MFC can be operated at any temperature even though generally higher temperature could lead to increase electrical power generation [3]. With regard to $\mathrm{pH}$, neutral or slightly alkaline condition ( $\mathrm{pH}$ range $7-8$ ) is most favorable environment for the growth of electrogenic bacteria and methanogenic bacteria which lead to higher power and biogas production [4]. Higher HRT usually increase organic removal efficiency due to longer time for microbes to grow. However, study showed that high HRT would decrease the power density production [5].

SRT is considered as one of the most crucial parameters in determining the performance of MFC. The behavior and growth of anaerobic bacteria can be improved by the increment of SRT. Long operating SRT could provide a more conducive environment for the microorganisms to grow and degrades the organic pollutant more efficiently [6]. On the other hand, short operating SRT can hold incomplete biodegradation and washout of microbes from the system faster than they grow. Besides, feed concentration is another challenging task that decides the performance of MFC. Despite the fact that high concentration of feed could achieve high biogas yield due to its high organic content, it could also decrease the power density due to the substrate inhibition effect [7-8].

\footnotetext{
* Manuscript received March 21, 2018 ; revised March 7, 2019.

Corresponding author: Tel: (60) 468 8888; E-mail address: ngca@utar.edu.my

doi: $10.12720 /$ sgce.8.3.282-290
} 
The addition of powdered activated carbon (PAC) is renowned for its ability to improve the biological treatment efficiency [9]. Addition of PAC into activated sludge could lead to the transformation of biological activated carbon (BAC) [10-11]. Simultaneous processes of adsorption and biodegradation by BAC would promote the attachment of microorganisms and formation of biofilm, which eventually improve the treatment efficiency [12]. However, there is still no much studies are carried out to investigate the performance of MFC added with PAC.

\section{Materials and Methods}

\subsection{Materials}

Extra pure charcoal powdered activated carbon (PAC) supplied by GENE Chem company was used in this study. The seed of the anaerobic activated sludge and palm oil mill effluent (POME) were taken from a local palm oil mill which is owned by Tian Siang Group and located in Perak, Malaysia. The carbon clothes used as anode and cathode in this study were obtained from Fuel Cell Earth company. The MFCs used in this study is one of the MFC types namely single chamber air cathode fuel cell.

\subsection{Operations of microbial fuel cells (MFCs)}

Nine 0.5L MFCs as per Table 1 were set up. All MFCs were added with $1 \mathrm{~g} / \mathrm{L}$ of PAC except A-30 (Without PAC). A-series of MFCs (A-30, A-50, A-70 and A- $\infty$ ) were fed with high concentration of POME $(34,127 \mathrm{mg} / \mathrm{L} \mathrm{COD)}$ while B-series MFCs (B-30, B-50, B-70 and B- $\infty$ ) were fed with low concentration POME $(23,769 \mathrm{mg} / \mathrm{L} \mathrm{COD})$. All the MFCs were cultivated at ambient temperature and their $\mathrm{pH}$ is maintained at 7-8.

Table 1. Information on the MFCs involved in the study.

\begin{tabular}{|c|c|c|c|c|}
\hline Name of MFC & $\begin{array}{c}\text { Working } \\
\text { volume }(\mathrm{L})\end{array}$ & Type of MLSS & $\begin{array}{c}\text { SRT } \\
\text { (days) }\end{array}$ & $\begin{array}{l}\text { Feed concentration } \\
\qquad\left(\mathrm{mgL}^{-1}\right)\end{array}$ \\
\hline A-30 (without PAC) & \multirow{9}{*}{0.5} & $\begin{array}{c}\text { Anaerobic activated } \\
\text { sludge }\end{array}$ & 30 & \\
\hline A-30 & & & 30 & \multirow{4}{*}{$34,127 \pm 1,000$} \\
\hline A-50 & & & 50 & \\
\hline A-70 & & Anaerobic activated & 70 & \\
\hline $\mathrm{A}-\infty$ & & sludge + PAC & pseudo infinity & \\
\hline B-30 & & & 30 & \multirow{4}{*}{$23,769 \pm 1,000$} \\
\hline B-50 & & & 50 & \\
\hline B-70 & & & 70 & \\
\hline $\mathrm{B}-\infty$ & & & pseudo infinity & \\
\hline
\end{tabular}

\subsection{Analytical methods}

Mixed liquor suspended solid (MLSS) and mixed liquor volatile suspended solid (MLVSS) were analyzed by following the procedures from Standard Method, $21^{\text {st }}$ Edition. Chemical Oxygen Demand (COD) of feedstock wastewater and final effluent were measured based on the Closed Reflux Colorimetric from Standard Method, 21st Edition. Electricity power density production was calculated by measuring the voltage of each MFC and using the power density formula as follows:

$$
P=\frac{\text { voltage }^{2}}{\text { resistance } \mathrm{X} \text { volume }}
$$


The $\mathrm{pH}$ value was determined using $\mathrm{pH}$ meter (Hanna HI 2550). The biogas production was collected and measured using the downward water displacement method at atmospheric pressure [13].

\section{Results and Discussion}

After the nine MFCs i) with and without PAC addition, ii) with different SRTs, and iii) with different feed concentrations had been cultivating for two months, their performance were assessed in terms of organic removal rate, biogas and electricity production rates. The results are as per Table 2 .

The organic pollutant removal efficiency, power and biogas production of different MFCs were found to be affected by SRT, substrate concentration and the presence of additive .The $\mathrm{pH}$ of each MFC was maintained in the range of 7.12 to 7.37 throughout the study. This indicated that the organic acids produced were effectively metabolized and created a favorable environment for the methanogenic and electrogenic bacteria to grow [4]. Hydraulic retention time (HRT) was fixed at 4 days whereas the F/M ratio was set at the range of 0.5-1.0 to prevent any influence on the performance.

\subsection{Treatment performance of MFCs with and without PAC}

The performance of MFCs added with and without PAC was investigated and the results were shown in Fig. 1 and Fig. 2. The MFC added with $1 \mathrm{~g} / \mathrm{L}$ of PAC showed better performance in terms of power density and biogas productions as compared to MFC without PAC addition. In Fig. 1, the highest power density obtained by the MFC added with PAC was $345.85 \mathrm{~mW} / \mathrm{m}^{3}$ whereas only $19.85 \mathrm{~mW} / \mathrm{m}^{3}$ of power density obtained by MFC without the PAC addition. As per Table 2, the average voltage and power density of MFC with PAC showed huge difference compared with MFC without PAC addition. Fro m Fig. 2, the total volume of biogas collected after about 26 days from MFC with PAC could reach $940 \mathrm{ml}$, which is $22.4 \%$ higher than MFC without PAC addition. This indicated that PAC could enhance the biological treatment ability by degrading the complex organic substances in POME into methane gas. In terms of COD removal rate, the MFC with PAC could achieve $57.31 \%$ of organic pollutant removal rate, which is $12.86 \%$ more than MFC without PAC.

It is proven that PAC could enhance the MFCs performance. This was because PAC is famous for its strong adsorption characteristics and able to produce better effluent quality through adsorption of the fine pollutants. The PAC added into activated sludge of MFCs would develop into biological activated carbon (BAC), thus promoted the attachment of microorganisms and biofilm formation on the anode surface[1012]. The BAC would encourage the simultaneous process of adsorption and biodegradation of organic pollutants, eventually improve the performance of MFCs. However, PAC has to be replenished after being desludged in order to maintain the PAC dosage in each MFCs except for MFC without PAC and MFCs with pseudo infinite SRT.

Based on Table 2, it shows that the total COD removal efficiencies of MFCs were increased along with prolonged SRT. The highest COD removal efficiency was obtained by MFC (A-70) with the SRT of 70 days and $34.1 \mathrm{~g} / \mathrm{L}$ of POME feed concentration. The prolonged SRT could promote microbial growth especially the anaerobic activated sludge with PAC and thus enhance the biodegradation of organic pollutants. The growth rate of bio mass could be also proven by the concentrations of MLSS and MLVSS of MFCs. A-70 had the highest MLVSS as compared to others. The addition of PAC into the MFCs showed significant difference in the biomass growth rate through the comparis on of A-30 (W ithout PAC) and A-30 in terms of MLSS and MLVSS. In the meantime, the microbial growth was also being affected by the POME feed concentration. The reduction in feed concentration from $34.1 \mathrm{~g} / \mathrm{L}$ (high concentration) to $23.7 \mathrm{~g} / \mathrm{L}$ (low concentration) had led to the reduction of MLSS and MLVSS. This may be due to deficiency of organic substrate as carbon source for microbes. Hence, the removal efficiency of the MFCs fed with lower feed concentration is lower as compared to the MFCs fed with higher feed concentration. 
Table 2. Treatment performance of MFCs at different operating conditions.

\begin{tabular}{|c|c|c|c|c|c|c|c|c|c|}
\hline Parameter & $\begin{array}{c}\text { A-30 } \\
\text { (Without } \\
\text { PAC) }\end{array}$ & A-30 & A-50 & A-70 & $\overline{A-\infty}$ & B-30 & B-50 & B-70 & $\bar{B}-\infty$ \\
\hline Temperature, ${ }^{\circ} \mathrm{C}$ & Ambient & Ambient & Ambient & Ambient & Ambient & Ambient & Ambient & Ambient & Ambient \\
\hline PAC dosage, $g / \mathrm{L}$ & 0 & & & & 1960 & 1 & & & \\
\hline HRT, d & & & & & 4 & & & & \\
\hline SRT, d & 30 & 30 & 50 & 70 & $\infty$ & 30 & 50 & 70 & $\infty$ \\
\hline Feed COD, $g / L$ & & & $34.1 \pm 1.0$ & & & \multicolumn{4}{|c|}{$23.7 \pm 1.0$} \\
\hline $\begin{array}{l}\text { Supernatant COD, } \\
\mathrm{g} / \mathrm{L}\end{array}$ & $19.0 \pm 3.0$ & $14.6 \pm 1.5$ & $13.6 \pm 1.4$ & $12.1 \pm 1.1$ & $14.8 \pm 1.8$ & $13.0 \pm 1.7$ & $12.5 \pm 1.6$ & $10.8 \pm 1.1$ & $15.8 \pm 1.7$ \\
\hline $\begin{array}{l}\text { COD removal } \\
\text { efficiency }\end{array}$ & $44.27 \pm 8.72$ & $57.31 \pm 4.54$ & $60.13 \pm 4.07$ & $64.40 \pm 3.24$ & $56.75 \pm 5.18$ & $45.49 \pm 7.45$ & $47.42 \pm 6.54$ & $54.75 \pm 4.80$ & $33.63 \pm 7.28$ \\
\hline MLSS, g/L & $13.17 \pm 1.10$ & $16.70 \pm 3.10$ & $17.66 \pm 2.26$ & $18.63 \pm 1.22$ & $15.77 \pm 1.33$ & $11.03 \pm 2.98$ & $13.77 \pm 1.83$ & $15.77 \pm 2.81$ & $14.07 \pm 2.13$ \\
\hline $\begin{array}{l}\text { MLVSS, g/L } \\
\text { F/M ratio }\end{array}$ & $11.70 \pm 1.36$ & $14.23 \pm 3.27$ & $15.05 \pm 2.30$ & $15.87 \pm 0.73$ & $\begin{array}{c}13.27 \pm 1.56 \\
0.5-1.0\end{array}$ & $9.50 \pm 3.00$ & $11.90 \pm 2.05$ & $13.43 \pm 2.40$ & $11.87 \pm 2.13$ \\
\hline $\mathrm{pH}$ & $7.12 \pm 0.18$ & $7.22 \pm 0.20$ & $7.25 \pm 0.15$ & $7.35 \pm 0.23$ & $7.37 \pm 0.23$ & $7.18 \pm 0.12$ & $7.31 \pm 0.15$ & $7.30 \pm 0.20$ & $7.26 \pm 0.18$ \\
\hline $\begin{array}{l}\text { Average biogas } \\
\text { yield } \mathrm{mL} / \mathrm{h}\end{array}$ & $30.07 \pm 3.19$ & $37.04 \pm 3.88$ & $39.37 \pm 3.98$ & $41.48 \pm 4.31$ & $34.52 \pm 3.30$ & $26.26 \pm 2.23$ & $27.41 \pm 2.32$ & $27.59 \pm 2.30$ & $22.44 \pm 1.98$ \\
\hline $\begin{array}{l}\text { Average voltage, } \\
\mathrm{mV}\end{array}$ & 6.98 & 35.62 & 66.20 & 105.96 & 6.26 & 130.31 & 148.93 & 161.61 & 1.16 \\
\hline $\begin{array}{l}\text { Average power } \\
\text { density, } \mathrm{mW} / \mathrm{m}^{3}\end{array}$ & 2.53 & 72.51 & 146.91 & 279.73 & 1.32 & 366.16 & 487.69 & 558.58 & 0.05 \\
\hline
\end{tabular}

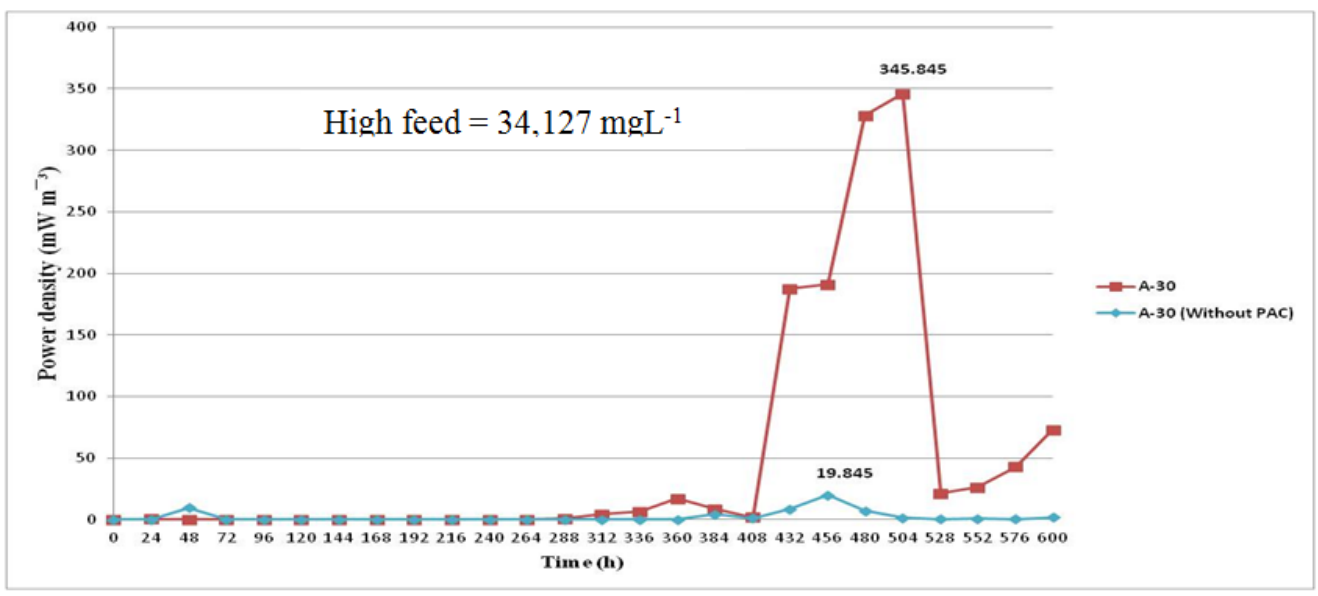

Figure 1. Power density over 600 hours for MFCs added with and without PAC.

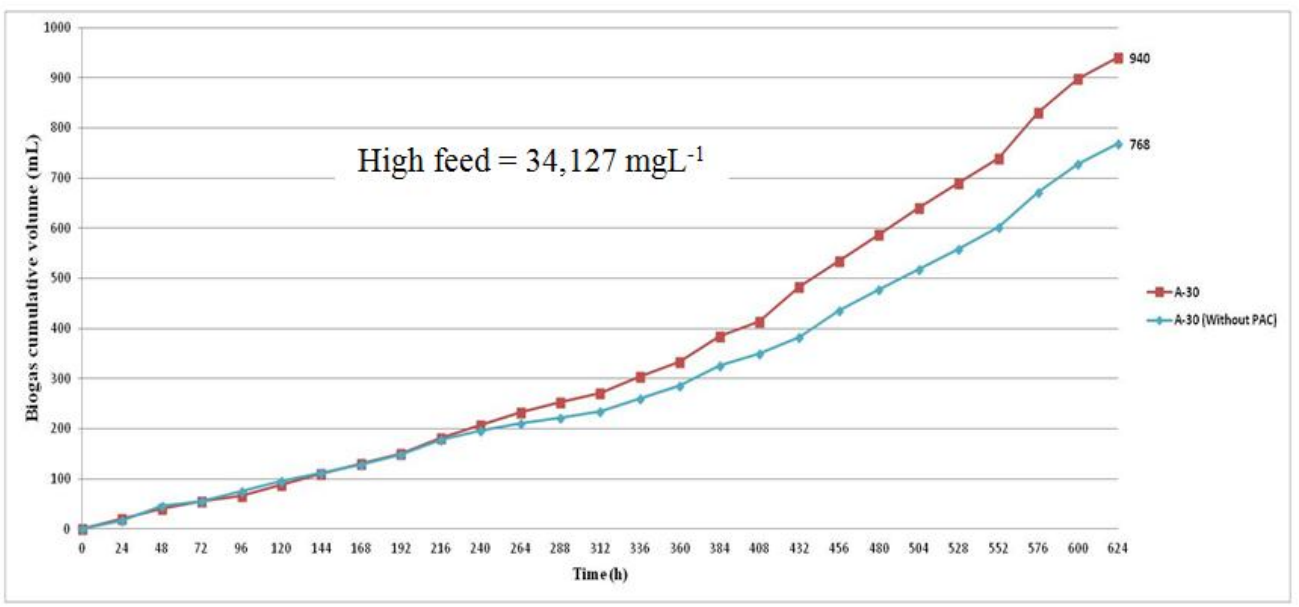

Figure 2. Biogas cumulative volumes over 624 hours for MFCs added with and without PAC. 


\subsection{Power generation ofMFCs controlled at different SRTs and fed with different POME concentrations}

The power generation over 600 hours for the nine MFCs was measured and calculated as per Fig. 3 and Fig. 4. Based on Fig. 4, the highest power density was achieved by B-70 at $1534.58 \mathrm{~mW} / \mathrm{m}^{3}$, followed closely by B- 50 at $1404.5 \mathrm{~mW} / \mathrm{m}^{3}$. Table 2 shows the same trend. The average power density obtained by B-70 is the highest at $558.58 \mathrm{~mW} / \mathrm{m}^{3}$. It was found that higher power density could be achieved with longer SRT. Prolonged SRT provided sufficient retention time for the enrichment and forming process of anaerobic electrogenic bacteria on the anode surface. On the other hand, shorter SRT MFCs such as A-30, A-50, B-30 and B-50 showed lower average power density output due to higher daily desludging process. SRT 30 days and SRT 50 days required daily sludge removal of $25 \mathrm{~mL}$ and $15 \mathrm{~mL}$ respectively whereas SRT 70 days only being desludged for about $10 \mathrm{~mL}$ daily. The shorter retention time limited the bacteria growth and biodegradation which had resulted in lower power density production. MFCs operated at SRT of pseudo infinite days showed the lowest average power density production among all MFCs. Pseudo infinite SRT indicated that no daily sludge removal but only daily removal of supernatant. This may cause aged anaerobic activated sludge and aged BAC to lose their ability to biodegrade and adsorption of pollutants, eventually led to biofilm fouling of electrodes. The biofilm fouling layer would increase the internal resistance and reduced the electron transfer, which resulted in low power production [14].

Besides that, the feed concentration could also affect the power density production. MFCs fed with high concentration of POME were only able to produce highest power density of $666.125 \mathrm{~mW} / \mathrm{m}^{3}$ as shown in Fig. 3 while MFCs fed with low feed concentration could produce highest power density of $691.92 \mathrm{~mW} / \mathrm{m}^{3}$ as per Fig. 4. However, the sudden increase of the high power density as per Fig. 3.4 was due to sudden increase in quantity of POME feed. The low in power production for high substrate concentration as per Fig. 3 was mainly due to internal resistance in MFCs. From Fig. 5 and Fig. 6, the gradient of the linear curve is the internal resistance, Rint $=\Delta \mathrm{V} / \Delta \mathrm{I}$ and Fig. 5 showed that high concentration of feed would have higher internal resistance and hence generate lower power density [15]. MFCs fed with high substrate concentration also increased the time needed to reach constant open circu it voltage (OCV). For instance A-70 required 456 hours to achieve the peak voltage while B-70 only needed 408 hours. The trends are as shown in Fig. 3 and Fig. 4. This is mainly attributed to the substrate inhibition effect. High concentration of substrate is more likely to have this effect where some of the substrates would inhibit the activity of microbes in biodegradation process. Inhibited microorganisms would lose its capability to continuously consume the carbon sources available in the substrate solution and as a result the constant OCV was achieved earlier at lower power output [7]. The power output of the MFCs as per Fig. 3 is lower than that of the MFCs as per Fig. 4.

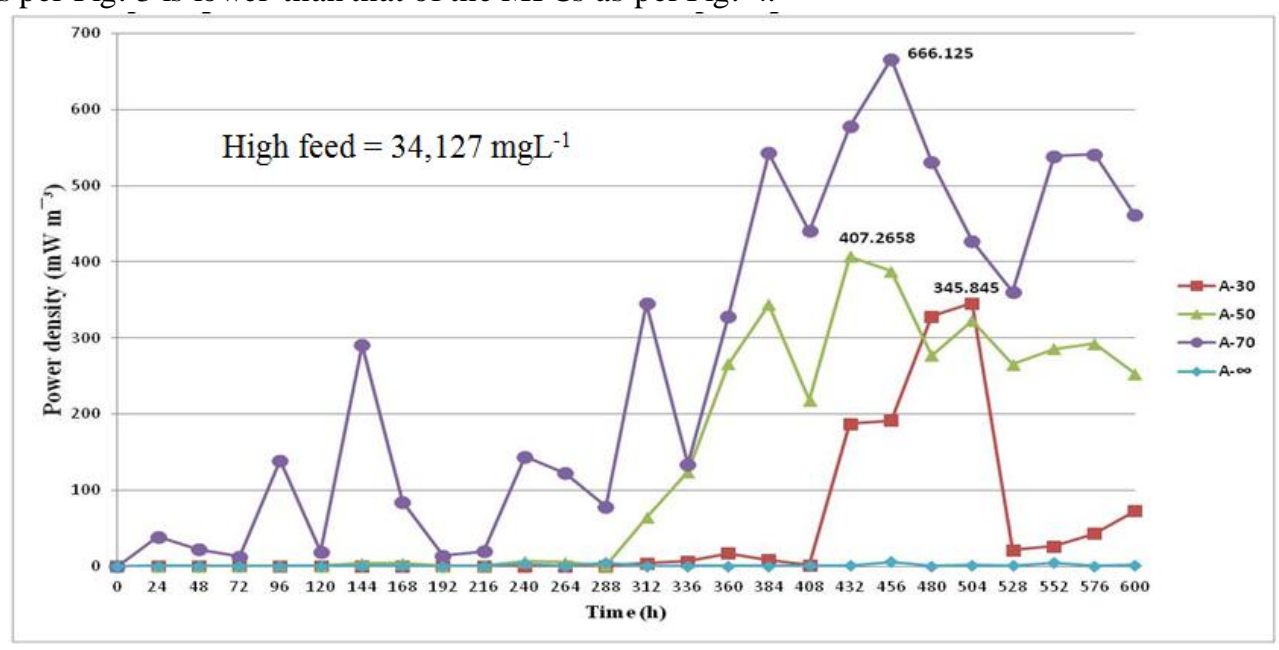

Figure 3. Power density over 600 hours for four high concentration feed MFCs. 


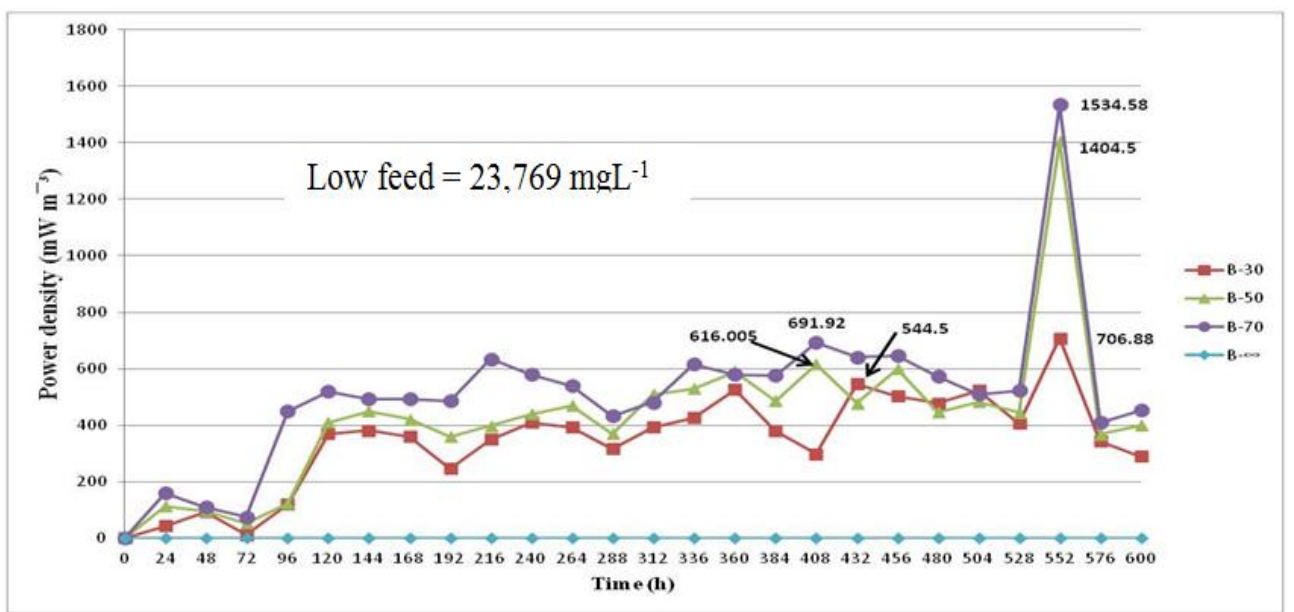

Figure 4. Power density over 600 hours for four low concentration feed MFCs.

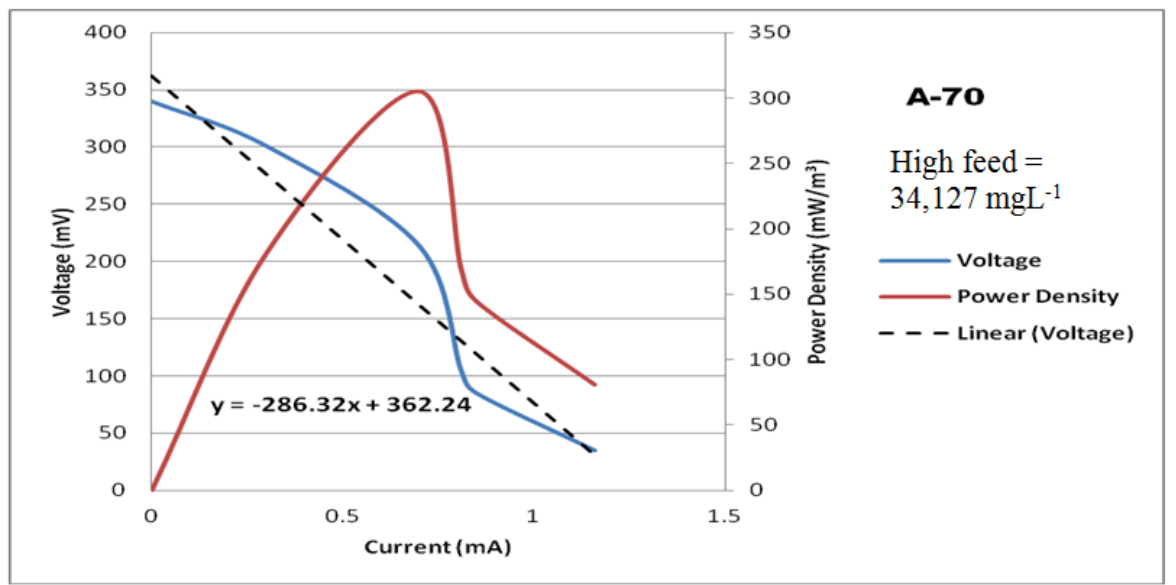

Figure 5. Polarization curve for SRT 70 days and high concentration feed MFC.

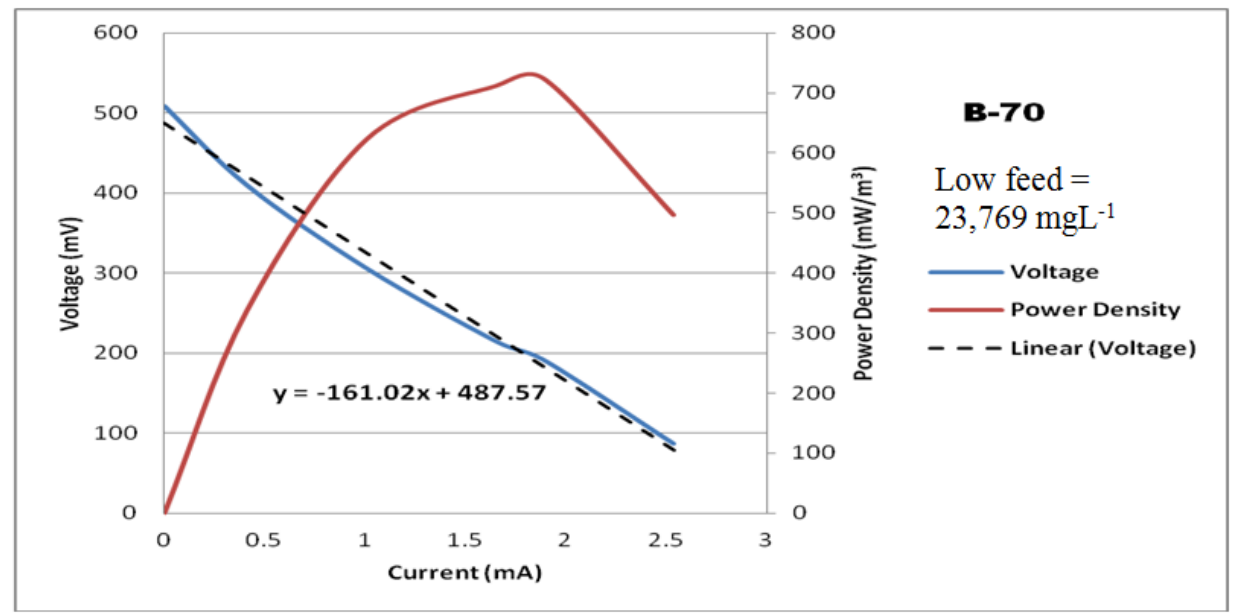

Figure 6. Polarization curve for SRT 70 days and low concentration feed MFC. 


\subsection{Effects of SRTs and feed concentration on biogas production ofdifferent MFCs}

The power generation over 624 hours for the nine MFCs was measured and calculated as per Fig. 7 and Fig. 8. High concentration of feed provides larger volume of organic matter, which is favorable for biogas production [8]. By comparis on between Fig. 7 and Fig. 8, MFCs fed with high concentration of POME could obtain relatively higher biogas production. Total volu me of biogas which could be collected by A-70 (Fig. 7) is $1040 \mathrm{~mL}$ over 624 hours whereas the MFCs fed with low concentration POME could only obtain total volume of biogas at $703 \mathrm{~mL}$ by B-70 (Fig. 8). The biogas production was imp roved up to $47.94 \%$ for the A-70 compared to B-70. In addition, SRT is also a crucial parameter in determining the biogas production as the microbial growth is closely related to the biogas production. With the $\mathrm{pH}$ and temperature were maintained at a favorable condition, the methanogenic bacteria growth could be enhanced by prolonging the sludge retention time. Therefore, the biogas production was increased as the SRT is prolonged as illustrated in Fig. 7 and Fig. 8. MFCs with the SRT of pseudo infinite showed the lowest biogas production for both the MFCs fed with different feed concentrations. It is believed that the less impressive performance of both the MFCs cultivated at pseudo infinite was due to the number of aged methanogenic bacteria in them increased faster than the young methanogenic bacteria growth due to absence of daily desludging process. As a result, BAC would slowly losing its adsorption capacity and its mesopores filled with products of dead microbial cells, which then led to reduction in microbial activity (Sirotkin et al., 2001; $\mathrm{Ng}$ et al, 2010; $\mathrm{Ng}$ et al, 2013) and resulted in lower biogas production.

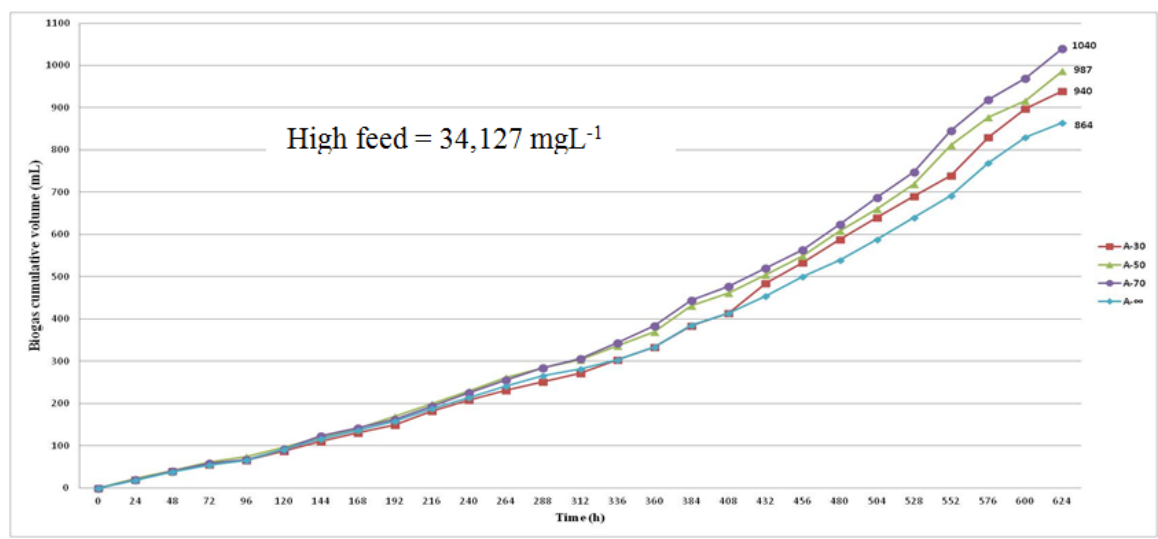

Figure 7. Biogas cumulative volumes over 624 hours for four high concentration feed MFCs.

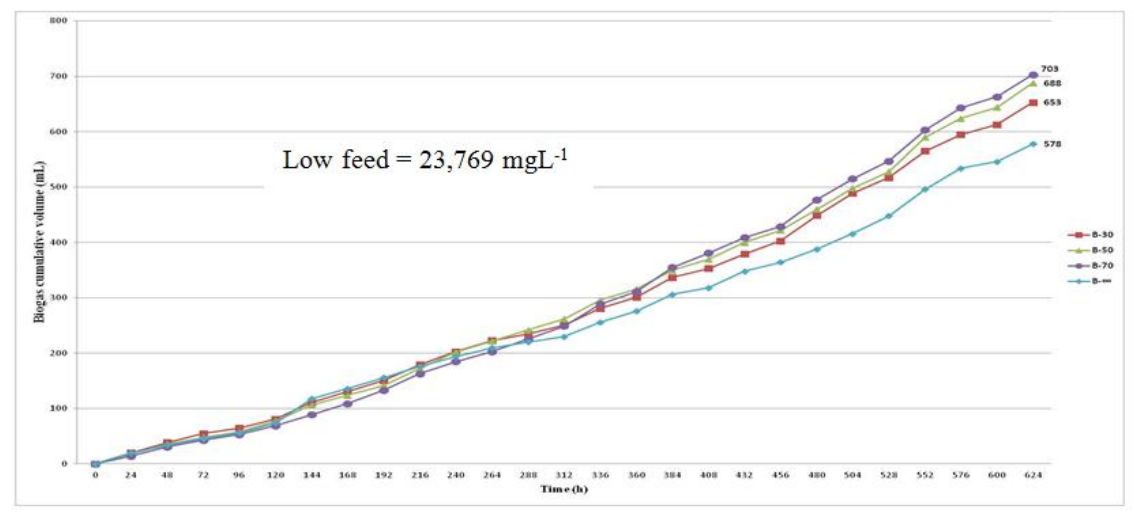

Figure 8. Biogas cumulative volumes over 624 hours for four low concentration feed MFCs. 


\section{Conclusion}

The treatment performance of MFCs with PAC addition cultivated at SRT of 70 days and fed with relatively higher feed concentration was the best MFC among others in terms of biogas production and COD removal efficiency. The addition of PAC, sludge retention time and feed concentration has been found to be the primary factor affecting the treatment performance in terms of biogas production and COD removal. Notable improvement in biogas production and COD removal under longer SRT and high feed concentration could be due to better microbial growth. The treatment performance of MFCs with PAC addition in terms of power density production is best for MFC cultivated at SRT 70 days but fed with relatively lower feed concentration. Power density of the MFC could improve significantly with longer SRT but with relatively low feed concentration. This could be due to the MFC had lower internal resistance and most of the carbon sources available in the relatively low concentration POME solution could be biodegraded more complete. This would help the MFC to produce higher voltage.

\section{Acknowledgments}

We would like to extend our g ratitude to Ministry of Science, Technology and Innovation (MOSTI) for the fund with project No. 03-02-11SF0161. No. 03-02-11SF0161 and Universiti Tunku Abdul Rahman for UTAR RESEARCH FUND with project No. IPSR/RMC/UTARRF/2015-C2/N02.

\section{References}

[1] Du Z, Li H, Gu T, 2007. A state of the art review on microbial fuel cells: A promising technology for wastewater treatment and bioenergy. Biotechnol. Adv. 25, 464-82.

[2] Aktan S, Bozkurt A, Emine UC, Burcu IY, Arslan N, Gucin F, Ulusoy I. Electricty generation by a mediat or-less microbial fuel cell using mixed culture. In: 1st International Syposium on Sustainable Development, June 9-10, 2009, Sarajevo, Bosnia and Herzegovina.

[3] Behera M, Murthy SS, Ghangrekar MM. Effect of operating temperature on performance of microbial fuel cell. Water Sci. Technol. 2011; 64(4), 917-22.

[4] Gil GC, Chang IS, Kim BH, Kim M, Jang JK, Park HS, Kim HJ, Operational parameters affecting the performance of a mediator-less microbial fuel cell. Biosens. Bioelectron. 2003; 18, 327-34.

[5] Liu $\mathrm{H}$ and Logan B. Electricity generation using air-cathode single chamber microbial fuel cell in the presence and absence of proton exchange membrane. Environ. Sci.Technol. 2004; 38: 4040-46.

[6] Huang X, Gui P, and Qian Y. Effect of sludge retention time on microbial behavior in a submerged membrane bioreactor. Process Biochemistry, 2001; 36: 1001-06.

[7] Ghoreyshi AA, Jafary T, Najafpour GD, Haghparast F. Effect of type and concentration of substrate on power generation in a dual chambered microbial fuel cell. In: World Renewable Energy Congress 2011, 8-13 May, 201 1, Linkoping, Sweden.

[8] Miyamoto M, Nakashimada Y and Uemiya S, 2015. Membrane reactors for biogas production and processing. [e-book] Sawston: Woodhead Publishing. Available at: Google Books https://books.google.com.my/books?id=fEW dBAAAQBAJ\&pg=P A357\&lpg=PA357dq=high+strength+and+low+strength+w astewater+biogas+production \& source=bl\& ot s=seKpSLANuA\&sig=jz0Iy0aiyvRPJGKdBiNBUrdMQQ0\&hl=en \&sa=X\&redir _esc $=\mathrm{y} \# \mathrm{v}=$ onepage $\& \mathrm{q}=$ high $\% 20$ strength $\% 20$ and $\% 20$ low\%20 strength $\% 20$ wastewater\%20biogas\%20product ion \&f=false > [Accessed 8 January 2016].

[9] Aghamohammadi N, Hamidi AA, Hasnain IM, Zinatizadeh AA, Nasrollahzadeh SH, Ghafari SH. Performance of a powdered activated carbon (PAC) augmented activated sludge process treating semi-aerobic leachate. Int. J. Environ. Res. 2006; 1(2): 93-103.

[10] Ng CA, Sun D, Zhang J, Wu B, and Fane AG. Mechanisms of fouling control in membrane bioreactor by the addition of powdered activated carbon. Separation Science and Technology, 2010; 45:873-89.

[11] Ng CA, Sun D, Mohammed JKB, Wai SH, Wong LY, Humaira Nisar, Wu B., Fane AG. Optimization of membrane bioreactors by the addition of powdered activated carbon, Bioresour. Technol. 2013; 138, 38-47.

[12] Cecen F, 2011. Activated carbon for water and wastewater treatment: Integration of adsorption and biologicaltreat ment. 1st ed. Weinheim, Germany: WILEY-VCH Verlag GmbH \& Co. KGaA.

[13] Ajay KJ, Li JZ, Zhang LG, Ban QY, and Jin Y. Comparison between wet and dry anaerobic digestion of cow dung under mesophilic and thermophilic conditions. Advances in Water Resource and Protection (AWRP) 2013; 1(2): 28-38. 
[14] Li WW, Yu HQ, and He Z. Towards sustainable wastewater treatment by using microbial fuel cells-centered technologies. Energy Environ. Sci. 2013; 7:911-24.

[15] Logan B, Hamelers B, Rozendal R, Schroder U, Keller J, Freguia S, Aelterman P, Verstraete W, and Rabaey K. Microbial fuel cells methodology and technology.Environ. Sci.Technol. 2006; 40(17): 5181-92.

[16] Sirotkin AS, Koshkina LY, and Ippolitov KG. The BAC-process for treatment of wastewater containing non-ionogenic synthetic surfactants, Water Research, 2001; 35(13): 3265-71. 